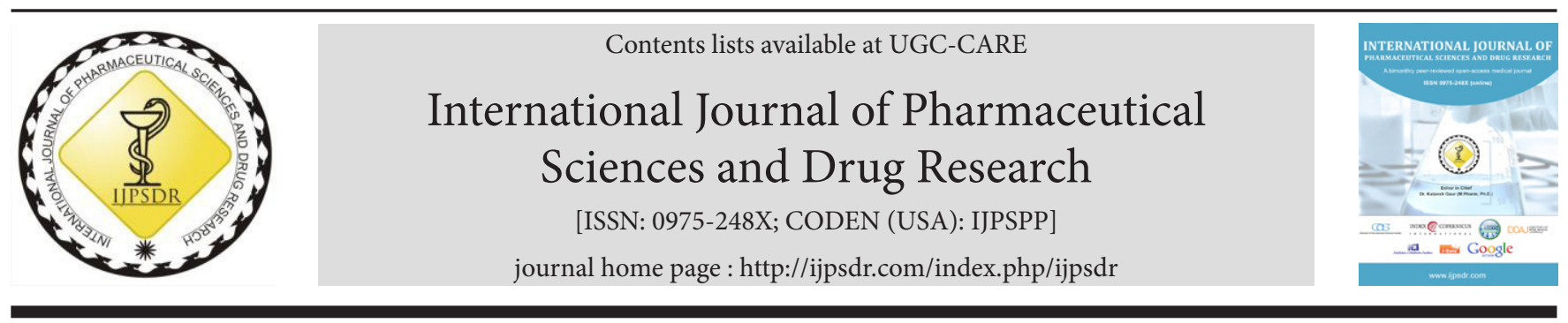

Research Article

\title{
Validation of In vitro Deposition of Emitted Dose Method for Simultaneous Estimation of Formoterol Fumarate and Glycopyrrolate in combined Dry Powder Inhaler Aerosol Pharmaceutical Dosage Form
}

\author{
Ravindra K. Kotak ${ }^{1 *}$, Chintan V. Pandya ${ }^{1}$, Aditee C. Pandya ${ }^{2}$ \\ ${ }^{1}$ Kadi Sarva Vishwavidyalaya, Nr. Kh-5 Circle, Sector-15, Gandhinagar-382015, Gujarat, India \\ ${ }^{2}$ School of Sciences, P. P. Savani University, Surat-394125, Gujarat, India
}

\author{
ART ICLE INFO \\ Article history: \\ Received: 23 May, 2020 \\ Revised: 27 June, 2020 \\ Accepted: 10 August, 2020 \\ Published: 30 September, 2020 \\ Keywords: \\ Dry powder inhaler, \\ Formoterol fumarate, \\ Glycopyrrolate, \\ High performance liquid \\ chromatography (HPLC) \\ Respicaps, \\ Validation. \\ DOI: \\ 10.25004/IJPSDR.2020.120511
}

\begin{abstract}
A B S T R A C T
Formoterol fumarate and glycopyrrolate dry powder inhaler is a combined pharmaceutical aerosol dosage form. The label claim of this combined dosage form is $6 \mathrm{mcg}$ of formoterol fumarate and $25 \mathrm{mcg}$ of glycopyrrolate per respicap. It is prescribed for the treatment of asthma and chronic obstructive pulmonary disease. The deposition of an emitted dose is an in vitro investigational test that provides the idea of drug deposition inside the patient's lung. The present study aimed to validate the high performance liquid chromatography (HPLC) method to determine the deposition of the emitted dose of these analytes. This validation study was performed according to International Conference on Harmonization (ICH) guidelines and covers precision, linearity, accuracy, robustness, ruggedness, stability of analytical solution, and specificity. The reversed-phase chromatographic method uses a mobile phase prepared by mixing buffer containing sodium sulfate with ion pair reagent, acetonitrile, methanol, and purosphere star $125 \mathrm{~mm}$ column, $1 \mathrm{~mL}$ per minute flow rate, $215 \mathrm{~nm}$ wavelength, $25^{\circ} \mathrm{C}$ column oven, and $100 \mu \mathrm{L}$ injection volume. The method found linear over the range of 10 to $150 \%$ of target concentration with a correlation coefficient of 0.9997 for formoterol and 0.9999 for glycopyrrolate. The recoveries obtained were 103.1 to $103.8 \%$ for formoterol and 97 to $100.1 \%$ for glycopyrrolate. The fine particle dose, mass balance, and \% RSD were found well within the precision acceptance criteria. No interference found at the retention time of analyte peaks in blank, placebo, and degradation conditions describe method specificity. The method showed a successful application for the determination of formoterol fumarate and glycopyrrolate in dry powder inhaler pharmaceutical formulation.
\end{abstract}

\section{INTRODUCTION}

Asthma and chronic obstructive pulmonary disease (COPD) are types of obstructive lung disease. The main symptoms of COPD include shortness of breath and cough with sputum production. COPD is a progressive disease, which means it typically increases and becomes worse with time.

Formoterol fumarate is a bronchodilator that dilates the bronchi and bronchioles, decreases resistance in the respiratory airway, increases airflow to the lungs, and is used in the treatment of asthma. ${ }^{[1-3]}$
Glycopyrrolate, also known as glycopyrronium bromide, is a quaternary ammonium compound that is an anticholinergic drug. Glycopyrrolate blocks muscarinic receptors, thus, inhibiting cholinergic transmission. It is used to inhibit salivation and excessive secretions of the respiratory tract preoperatively, the reversal of neuromuscular blockade, and peptic ulcer. ${ }^{[4]}$ Aerosol dosage form has many advantages over classical pharmaceutical dosage forms. Dry powder inhalers are administered by mouth, using a suitable device, and reach directly to the patients' lungs to give the desired local effect in terms of fast relief and easy breathing. ${ }^{[5-7]}$

\footnotetext{
"Corresponding Author: Ravindra K. Kotak

Address: Kadi Sarva Vishwavidyalaya, Near Kh-5 Circle, Sector-15, Gandhinagar-382015, Gujarat, India

Email $\square$ : kotakravindrak@gmail.com

Tel.: +91-9998991984

Relevant conflicts of interest/financial disclosures: The authors declare that the research was conducted in the absence of any commercial or financial relationships that could be construed as a potential conflict of interest.

Copyright (C) 2020 Ravindra K. Kotak et al. This is an open access article distributed under the terms of the Creative Commons AttributionNonCommercial-ShareAlike 4.0 International License which allows others to remix, tweak, and build upon the work non-commercially, as long as the author is credited and the new creations are licensed under the identical terms.
} 
Analytical method development and validation for dry powder inhaler formulation is challenging work as the dose range is very low in microgram levels. The present validation study showed a successful application for determining formoterol fumarate and glycopyrrolate in the concentration range of 0.06 to $0.88 \mu \mathrm{g} / \mathrm{mL}$ and 0.25 to $3.75 \mu \mathrm{g} / \mathrm{mL}$, respectively. ${ }^{[8-11]}$ Very limited analytical methods have been reported in the literature to estimate formoterol fumarate and glycopyrrolate drugs in combined aerosol formulation, which includes different chromatographic techniques, mainly with gradient elution, long runtime, and more usage of solvents and hence, less cost-effective. ${ }^{[12-14]}$ The present investigation reports precise, linear, specific, rugged, and robust isocratic method with a short runtime, less usage of solvents, and hence, very much cost-effective for usage in the pharmaceutical industry and, guide future scientific researchers.

\section{MATERIALS AND METHODS}

\section{Chemicals and Reagents}

Formoterol fumarate dihydrate used for this study is manufactured by Vamsi Labs Limited. Glycopyrrolate used for this study is manufactured by Harman Phenochem Limited, and formoterol fumarate and glycopyrrolate respicaps are manufactured by Zydus Cadila Healthcare Limited. These standards, samples, and Respihaler Device for inhalation are provided by Zydus Cadila Healthcare Limited, Ahmedabad, India. The study was performed at Pharmaceutical Technology Centre, an analytical development laboratory of Zydus Cadila Healthcare Limited. Reagents sodium sulfate, 1-hexane sulfonic acid sodium salt monohydrate, sulfuric acid, methanol, and acetonitrile used is manufactured by Merck Limited.

\section{Instrument and Chromatographic System}

Chromatographic separation and quantification of the deposition of the emitted dose of formoterol fumarate and glycopyrrolate were performed using the Shimadzu and Agilent HPLC system. The systems have a quaternary solvent manager, a sample manager, and column oven, with ultraviolet (UV) and diode array detector. The output signal monitoring and processing were done using LC solution and Chromeleon software. The separation was
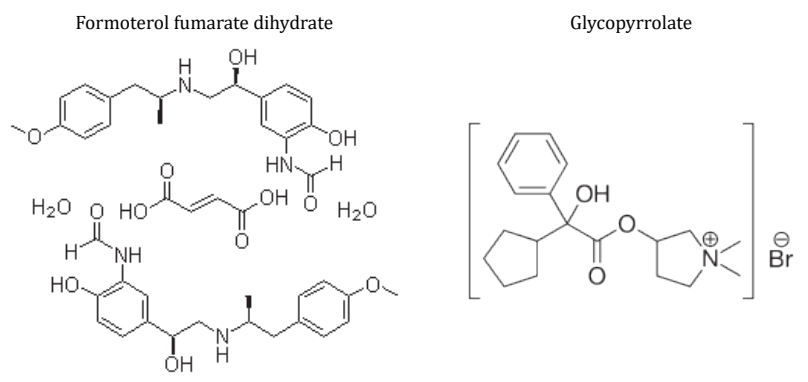

Fig. 1: Structure of drug molecules achieved on Purosphere Star RP 18e $(125 \times 4.6 \mathrm{~mm} \times 5 \mu \mathrm{m})$ column. The isocratic liquid chromatographic method employs mobile phase prepared by adding 1.6 grams of sodium sulfate anhydrous, 0.5 -gram of 1-hexane sulfonic acid sodium salt monohydrate, and $3 \mathrm{~mL}$ of dilute sulfuric acid (0.5-gram in $100 \mathrm{~mL}$ purified water) to $1,000 \mathrm{~mL}$ HPLC grade water, and dissolved with the help of shaking with a glass rod and ultrasonication. ${ }^{[12]}$ The solution was filtered through a $0.45 \mu$ nylon filter and degas. This buffer solution, acetonitrile, and methanol are mixed in the ratio of $680: 240: 80 \mathrm{~mL}(68: 24: 8 \% \mathrm{v} / \mathrm{v} / \mathrm{v})$. The mobile phase was pumped with a flow rate of $1 \mathrm{~mL}$ per minute. The column oven temperature was maintained at $25^{\circ} \mathrm{C}$, and the injection volume was kept as $100 \mu \mathrm{L}$. The detection was monitored at a wavelength of $215 \mathrm{~nm}$. The mixture of buffer solution and methanol in the ratio of $620: 380 \mathrm{~mL} 662: 38$ $\% \mathrm{v} / \mathrm{v}$ ) is used as a diluent. The structure of drug molecules is shown in Fig. 1. ${ }^{[15-18]}$

\section{Standard and Sample Preparation}

Standard solution of formoterol fumarate and glycopyrrolate was prepared at a concentration of 0.6 and $2.5 \mu \mathrm{g} / \mathrm{mL}$, respectively, by dissolving the appropriate amount of drug substance standard in the diluent. The sample was prepared using the following procedure; introduced $7 \mathrm{~mL}$ diluent into the upper and $30 \mathrm{~mL}$ diluent into the lower impingement chamber and connected all the assembly component parts, as shown in Fig. 2. Arranged assembly vertical and adequately supported, and the lower jet-spacer peg of the lower jet assembly touches the lower impingement chamber's bottom; connected a suitable vacuum pump and critical flow controller to the outlet of the apparatus. Adjusted the airflow through the apparatus, as measured at the inlet to the throat, to $60 \pm 5$ liters per minute, attached mouthpiece to assembly. Took ten respicaps for testing. Placed one capsule inside Respihaler device, pierce it by pressing the blue press buttons on the device. Attached the device with assembly. Set time of 4 seconds to the critical flow controller and

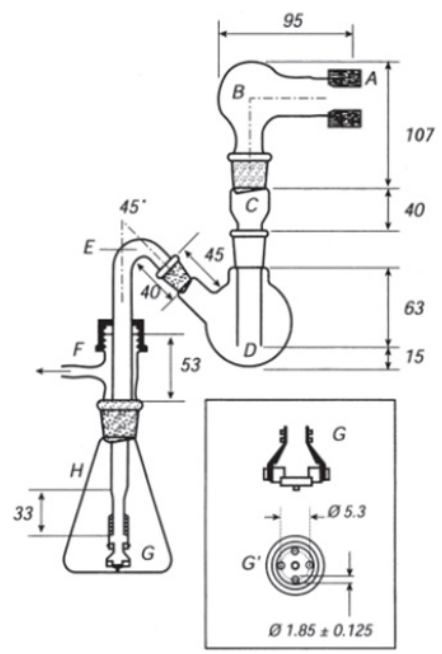

Fig. 2: Twin stage liquid impinger assembly 
started the pump. After 4 seconds, the flow automatically stopped with the help of the critical flow controller, and the dose inside the capsule reached different parts of the assembly. Removed the empty capsule from the device. Now placed the second capsule inside Respihaler device, pierce and repeated procedure same as the first capsule. This procedure was performed for all 10 respicaps. Dismantled the apparatus, and samples should be prepared for upper impingement chamber $\mathrm{T} 1$ and lower impingement chamber $\mathrm{T} 2$.

\section{Upper Impingement Chamber T1 Sample Preparation}

Washed the mouthpiece and all parts of the upper impingement chamber with diluent and transferred into $100 \mathrm{~mL}$ volumetric flask with suitable funnel. Again rinsed all parts of upper impingement chamber and transferred solution into same $100 \mathrm{~mL}$ volumetric flask. Made volume up to a mark of $100 \mathrm{~mL}$ with diluent.

\section{Lower Impingement Chamber T2 Sample Preparation}

Washed the coupling tube and lower impingement chamber with diluent and transferred into $100 \mathrm{~mL}$ volumetric flask with the help of a suitable funnel. Again rinsed inner surfaces of lower impingement chamber and transferred solution into the same $100 \mathrm{~mL}$ volumetric flask. Made volume up to mark of $100 \mathrm{~mL}$ with diluent.

\section{Method Validation}

The developed analytical method was validated for its acceptable performance to ensure the suitability of the indent purpose. The validation parameters executed include accuracy, precision, specificity, linearity, range, ruggedness, and robustness experiments, per ICH guideline Q2 (R1).

\section{System Suitability and System Precision}

System suitability and system precision are determined by injecting multiple injections of the same standard

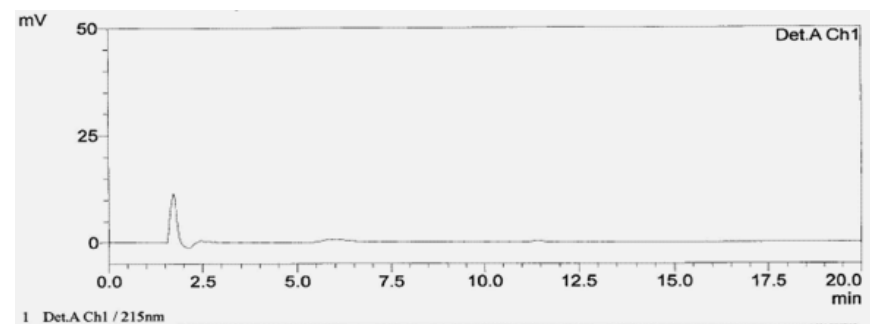

Fig. 3: Chromatogram of diluent

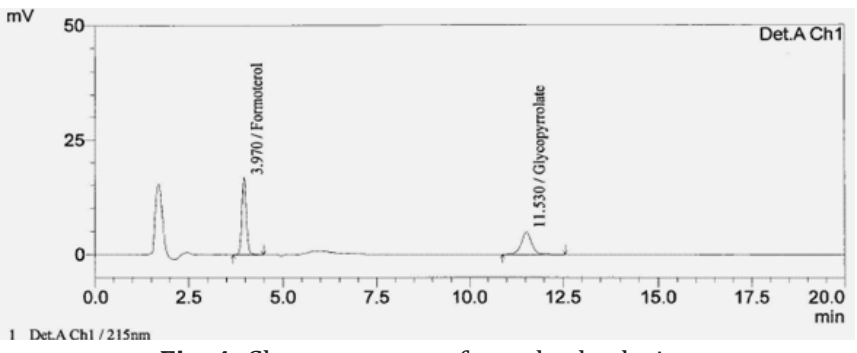

Fig. 4: Chromatogram of standard solution preparation and calculating the \% RSD for peak area of formoterol fumarate and glycopyrrolate. The theoretical plates and tailing factor were also recorded for formoterol fumarate and glycopyrrolate peaks.

The acceptance criteria were set to \% RSD of multiple injections should not be more than $2 \%$. The theoretical plates for formoterol and glycopyrrolate peaks should be not less than 1,500, and the tailing factor for each peak should be less than 2. Chromatograms of Diluent and standard preparation shown in Figs. 3 and 4, respectively.

\section{Linearity and Range}

The linearity of an analytical methodology is ability (within a given range) to obtain test results that are directly proportional to the concentration (amount) of analyte in the sample matrix. Linearity was studied by analyzing the mixed calibration standard solutions at ten concentration levels. The linearity solutions were prepared from 10 to $150 \%$ level of target concentration for glycopyrrolate for formoterol fumarate. The Y-intercept, slope, and correlation coefficient were calculated for both analytes from the linear regression equation. The specification was set to the value of correlation coefficient $R$ should not be less than 0.998 for all analytes. Y-intercept bias should not be more than $2 \%$ of the area of $100 \%$ linearity level. Linearity plot for absorbance vs. Concentration for formoterol fumarate and glycopyrrolate are shown in Figs. 5 and 6, respectively.

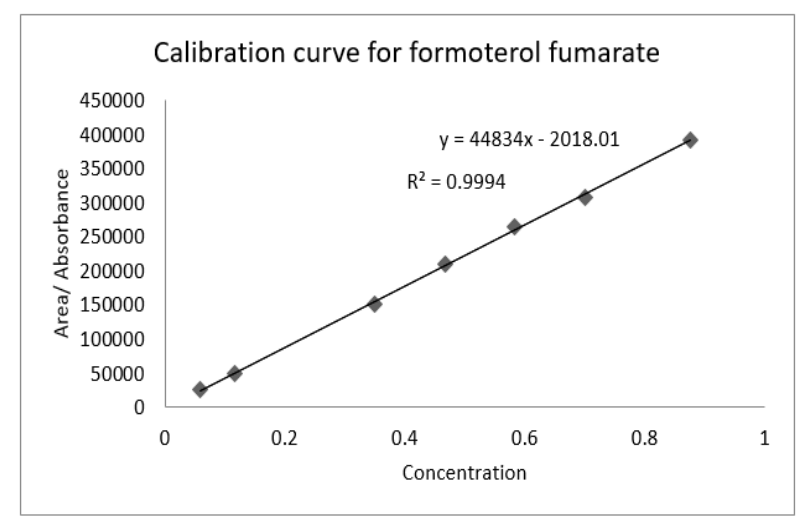

Fig. 5: Linearity plot for formoterol fumarate

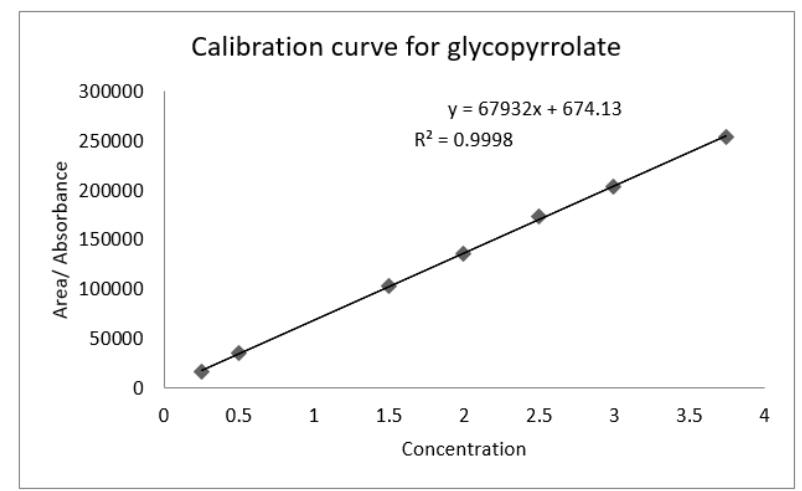

Fig. 6: Linearity plot for glycopyrrolate 


\section{Accuracy}

The accuracy is sometimes also referred to as recovery. The accuracy can be defined as the closeness of the measured value (actual concentration) to the true value (theoretical concentration). Recovery is defined as how much drug was recovered from the added concentration using the proposed method.

Recovery was evaluated in triplicate by the addition of three sets of formoterol fumarate and glycopyrrolate standard to the formula placebo to get concentration at 10,100 , and $150 \%$ level of the target concentration. The specification set for accuracy is 95 to $105 \%$, and \% RSD should not be more than $5 \%$.

\section{Method Precision}

Method precision study was performed by preparing ten same homogeneous sample preparations using a single batch. In vitro, fine particle dose and mass balance of formoterol fumarate and glycopyrrolate were calculated for all sample preparations. The mean of all results and percentage related standard deviation was also determined.

The specification was set for the percentage of the drug from lower impingement chamber $\mathrm{T} 2$ value for each individual set should not be less than $25 \%$, and mass balance of all sample preparation should not be less than $85 \%$.

\section{Stability of Analytical Solutions}

The stability of the analytical solution was determined by injecting standard and sample solutions at different time intervals up to 36 hours. The \% RSD of the peak area of formoterol fumarate and glycopyrrolate was measured. The specification set to \% RSD should not be more than $2 \%$ for both analytes.

\section{Intermediate Precision (Ruggedness)}

Intermediate precision expresses within-laboratories variations: different days, different columns, different equipment, etc. The study was performed by preparing ten same homogeneous sample preparations using a single batch. On a different day, by using a different lot of HPLC columns and by using different HPLC equipment. The specification was set the same as method precision study.

\section{Robustness}

The robustness of an analytical procedure is a measure of Table 1: System suitability and system precision

\begin{tabular}{llll}
\hline S. No. & $\begin{array}{l}\text { Parameters } \\
(n=5)\end{array}$ & $\begin{array}{l}\text { Formoterol } \\
\text { fumarate }\end{array}$ & Glycopyrrolate \\
\hline 1 & Retention time (min) & 4.02 & 11.62 \\
2 & Theoretical plates & 4,634 & 7,295 \\
3 & Tailing factor & 1 & 0.9 \\
4 & \% RSD & 0.1 & 0.2 \\
\hline
\end{tabular}

its capacity to remain unaffected by small but deliberate variations in method parameters and provides an indication of its reliability during normal usage. It was studied by making the following variations in the method.

- The column oven temperature was changed to $+5^{\circ} \mathrm{C}\left(20^{\circ} \mathrm{C}\right.$ for -temperature condition and $30^{\circ} \mathrm{C}$ for +temperature condition).

- The flow rate was changed by $+10 \%(0.9 \mathrm{~mL}$ per minute for -flow condition and $1.1 \mathrm{~mL}$ per minute for +flow condition).

- Mobile phase ratio was changed to +2 units absolute for buffer:acetonitrile:methanol (70:23:7 \%v/v/v for -organic condition and 66:25:9 \%v/v/v for +organic condition).

The system suitability criteria should be achieved for each changed condition during the robustness study.

\section{Specificity}

Specificity is the ability to assess the analytes unequivocally in the presence of components, which may expect to be present. Typically these might include placebo components, impurities, etc. The following solutions were prepared and injected into the HPLC system with a diode array detector to establish the specificity of the method.

- Mobile phase/ Diluent preparation

- Standard preparation

- Placebo preparation

- As such sample preparation (test preparation)

- Acid hydrolysis sample

- Alkali hydrolysis sample

- Peroxide oxidation sample

- Humidity degradation sample

- UV degradation sample

These samples were analyzed with a diode array detector, and the purity of analyte peaks was determined. The acceptance criteria were set to peak purity, should be greater than 990 for each peak. The degradation in the assay should be achieved between 10 to $30 \%$ in any one condition.

\section{RESULTS}

\section{System Suitability and System Precision}

System suitability and System precision data shown in Table 1 . The Low percentage RSD value shows system is precise and suitable for estimation of Formoterol Fumarate and Glycopyrrolate.

\section{Linearity and Range}

Linearity data shown in Table 2, Y-intercept bias is found $0.76 \%$ for formoterol fumarate and $0.39 \%$ for glycopyrrolate with respect to the area of $100 \%$ linearity level indicates the method is linear.

\section{Accuracy}

As shown in Tables 3 and 4, Accuracy at each individual level was found between 95 to 105\%, and \% RSD was found 
less than $5 \%$. This indicates that the method is accurate over the range of 10 to $150 \%$ of the target concentration.

\section{Method Precision (Repeatability)}

As shown in Table 5, the percentage of the drug from the lower impingement chamber T2 value for each individual set is greater than $25 \%$, and the mass balance of all sample preparation is higher than $85 \%$. This indicates that the method is precise.

As shown in Tables 6 and 7, the \% difference in the area at each level is less than $2 \%$. The standard and sample

\section{Stability of Analytical Solution}

solutions are stable at room temperature for 36 hours.

\section{Intermediate Precision (Ruggedness)}

Intermediate precision data is shown in Tables 8 and 9. The same procedure followed as method precision but on different days, on different HPLC instruments and different column lot, using the same sample as specified under precision.

The absolute difference observed between method precision and intermediate precision is less than $5 . \% \mathrm{~T} 2$ of all individual sets, as well as, $\%$ mass balance also found well within the specified criteria with changing in the day, HPLC column, and HPLC instrument. This indicates that the method is rugged.

Table 2: Linearity data of formoterol fumarate and glycopyrrolate

\begin{tabular}{|c|c|c|c|c|}
\hline Linearity level (\%) & $\begin{array}{l}\text { Final concentration in } \\
\mu \mathrm{g} / \mathrm{mL} \text { (formoterol fumarate) }\end{array}$ & Area & $\begin{array}{l}\text { Final concentration in } \\
\mu \mathrm{g} / \mathrm{mL} \text { (glycopyrrolate) }\end{array}$ & Area \\
\hline 10 & 0.0584 & 25,423 & 0.2495 & 16,627 \\
\hline 20 & 0.1167 & 50,038 & 0.499 & 34,734 \\
\hline 60 & 0.3502 & 151,424 & 1.497 & 103,093 \\
\hline 80 & 0.467 & 209,005 & 1.996 & 135,503 \\
\hline 100 & 0.5837 & 264,059 & 2.495 & 172,799 \\
\hline 100 & 0.7005 & 306,865 & 2.994 & 203,224 \\
\hline 150 & 0.8756 & 392,268 & 3.7425 & 253,985 \\
\hline
\end{tabular}

Table 3: Accuracy data of formoterol fumarate

\begin{tabular}{|c|c|c|c|c|c|}
\hline \multicolumn{6}{|c|}{ For formoterol fumarate } \\
\hline Level (\%) & $\begin{array}{l}\text { Amount of drug added } \\
\text { (mg) }\end{array}$ & $\begin{array}{l}\text { Amount of drug recovered } \\
(\mathrm{mg})\end{array}$ & Recovery (\%) & Mean (\%) & $\% R S D$ \\
\hline \multirow{4}{*}{10} & 0.0117 & 0.0121 & 103.4 & \multirow{4}{*}{103.1} & \multirow{4}{*}{1.3} \\
\hline & 0.0117 & 0.0122 & 104.3 & & \\
\hline & 0.0117 & 0.0119 & 101.7 & & \\
\hline & 0.1169 & 0.1206 & 103.2 & & \\
\hline \multirow[t]{3}{*}{100} & 0.1169 & 0.1206 & 103.2 & \multirow[t]{3}{*}{103.5} & \multirow[t]{3}{*}{0.6} \\
\hline & 0.1169 & 0.1218 & 104.2 & & \\
\hline & 0.1816 & 0.1819 & 103.6 & & \\
\hline \multirow[t]{2}{*}{150} & 0.1816 & 0.182 & 103.8 & \multirow[t]{2}{*}{103.8} & \multirow[t]{2}{*}{0.2} \\
\hline & 0.1816 & 0.1823 & 104 & & \\
\hline \multicolumn{6}{|c|}{ Table 4: Accuracy data of glycopyrrolate } \\
\hline \multicolumn{6}{|c|}{ For glycopyrrolate } \\
\hline Level (\%) & $\begin{array}{l}\text { Amount of drug added } \\
\text { (mg) }\end{array}$ & $\begin{array}{l}\text { Amount of drug recovered } \\
(\mathrm{mg})\end{array}$ & Recovery (\%) & Mean (\%) & $\% R S D$ \\
\hline \multirow{3}{*}{10} & 0.0499 & 0.0499 & 100 & \multirow{3}{*}{100.1} & \multirow{3}{*}{0.9} \\
\hline & 0.0499 & 0.0495 & 99.2 & & \\
\hline & 0.0499 & 0.0504 & 101 & & \\
\hline \multirow{3}{*}{100} & 0.499 & 0.4891 & 98 & \multirow{3}{*}{97.4} & \multirow{3}{*}{0.6} \\
\hline & 0.499 & 0.4836 & 96.9 & & \\
\hline & 0.499 & 0.4855 & 97.3 & & \\
\hline \multirow{3}{*}{150} & 0.7485 & 0.7277 & 97.2 & \multirow{3}{*}{97} & \multirow{3}{*}{1.1} \\
\hline & 0.7485 & 0.7335 & 98 & & \\
\hline & 0.7485 & 0.718 & 95.9 & & \\
\hline
\end{tabular}




\section{Robustness}

Robustness data is shown in Table 10. The RSD of five replicates of standard solution is less than $2 \%$ for all conditions. The theoretical plates for each analyte peak are higher than 1,500, and the tailing factor for each analyte peak is less than 2 . This indicates that the method is robust.

Table 5: Method precision data of formoterol fumarate and glycopyrrolate (TSLI)

\begin{tabular}{lllllll}
\hline & \% T1 & \multicolumn{3}{c}{$\%$ T2 } & \multicolumn{2}{c}{ \% mass balance } \\
\cline { 2 - 7 } Set no. & Formoterol fumarate & Glycopyrrolate & Formoterol fumarate & Glycopyrrolate & Formoterol fumarate & Glycopyrrolate \\
\hline 1 & 61 & 60 & 50 & 45 & 111 & 105 \\
2 & 59 & 61 & 40 & 48 & 99 & 109 \\
3 & 57 & 62 & 44 & 49 & 101 & 111 \\
4 & 58 & 62 & 48 & 49 & 106 & 111 \\
5 & 62 & 64 & 48 & 47 & 110 & 111 \\
6 & 64 & 67 & 50 & 44 & 114 & 111 \\
Mean & 60 & 47 & 47 & 107 & 110 \\
\hline
\end{tabular}

Table 6: Solution stability data for standard preparation

\begin{tabular}{lllll}
\hline \multirow{2}{*}{$\begin{array}{l}\text { Time } \\
\text { (hours) }\end{array}$} & Area & & \multicolumn{2}{c}{ \% difference from initial results } \\
\cline { 2 - 5 } Initial & Formoterol fumarate & Glycopyrrolate & Formoterol fumarate & Glycopyrrolate \\
6 & 283,925 & 195,372 & - & - \\
12 & 283,456 & 196,111 & 0.1 & 0.3 \\
18 & 283,568 & 195,856 & 0.1 & 0.2 \\
24 & 283,654 & 195,788 & 0.1 & 0.2 \\
30 & 283,384 & 195,410 & 0.1 & 0 \\
36 & 283,396 & 195,632 & 0.1 & 0.1 \\
\hline
\end{tabular}

Table 7: Solution stability data for sample preparation

\begin{tabular}{lllll}
\hline \multirow{2}{*}{$\begin{array}{l}\text { Time } \\
\text { (hours) }\end{array}$} & Area & \multicolumn{3}{c}{ \% difference from initial results } \\
\cline { 2 - 5 } Initial & Formoterol fumarate & Glycopyrrolate & Formoterol fumarate & Glycopyrrolate \\
6 & 283,376 & 195,117 & - & - \\
12 & 283,897 & 195,878 & 0 & 0.3 \\
18 & 284,512 & 195,463 & 0.2 & 0.1 \\
24 & 283,985 & 195,412 & 0 & 0.1 \\
30 & 284,685 & 195,521 & 0.2 & 0.1 \\
36 & 283,111 & 195,645 & 0.2 & 0.2 \\
\hline
\end{tabular}

Table 8: Intermediate precision data of formoterol fumarate and glycopyrrolate (TSLI)

\begin{tabular}{|c|c|c|c|c|c|c|}
\hline \multirow[b]{2}{*}{ Set no. } & \multicolumn{2}{|l|}{$\% T 1$} & \multicolumn{2}{|l|}{$\% \mathrm{~T} 2$} & \multicolumn{2}{|l|}{$\%$ mass balance } \\
\hline & Formoterol fumarate & Glycopyrrolate & Formoterol fumarate & Glycopyrrolate & Formoterol fumarate & Glycopyrrolate \\
\hline 1 & 56 & 59 & 52 & 44 & 108 & 103 \\
\hline 2 & 64 & 59 & 42 & 49 & 106 & 108 \\
\hline 3 & 57 & 61 & 49 & 44 & 106 & 105 \\
\hline 4 & 61 & 58 & 51 & 45 & 112 & 103 \\
\hline 5 & 65 & 65 & 49 & 45 & 114 & 110 \\
\hline 6 & 56 & 58 & 49 & 48 & 105 & 106 \\
\hline Mean & 60 & 60 & 49 & 46 & 109 & 106 \\
\hline$\%$ RSD & 6.8 & 4.5 & 7.2 & 4.7 & 3.4 & 2.8 \\
\hline
\end{tabular}


Validation of In vitro Deposition of Emitted Dose Method for Formoterol Fumarate and Glycopyrrolate

Table 9: Comparison of method precision and intermediate precision

\begin{tabular}{|c|c|c|c|c|}
\hline \multirow[b]{3}{*}{ Data comparison } & \multicolumn{2}{|l|}{ Method precision } & \multicolumn{2}{|l|}{ Intermediate precision } \\
\hline & \multicolumn{2}{|c|}{ Day-1/HPLC-1/Column-1 } & \multicolumn{2}{|c|}{ Day-2/ HPLC-2/Column-2 } \\
\hline & Formoterol fumarate & Glycopyrrolate & Formoterol fumarate & Glycopyrrolate \\
\hline$\% \mathrm{~T} 2$ mean & 47 & 47 & 49 & 46 \\
\hline$\%$ mass balance & 107 & 110 & 109 & 106 \\
\hline \multicolumn{3}{|c|}{ Absolute difference between assay results of method precision and intermediate precision } & 2 & 4 \\
\hline
\end{tabular}

Table 10: Robustness data

\begin{tabular}{|c|c|c|c|c|c|c|c|}
\hline \multicolumn{8}{|c|}{ For formoterol peak } \\
\hline Condition & As such & + Flow & -Flow & +Temp & -Тeтp & $+O r g$ & $-\mathrm{Org}$ \\
\hline Area & 109,877 & 100,071 & 121,236 & 109,583 & 109,624 & 109,534 & 108,404 \\
\hline Retention time & 3.91 & 3.56 & 4.33 & 3.75 & 4.09 & 3.34 & 4.68 \\
\hline Theoretical plates & 4,064 & 3,743 & 4,210 & 4,033 & 3,695 & 3,790 & 3,887 \\
\hline Tailing factor & 1.1 & 1.1 & 1.1 & 1.1 & 1.1 & 1.1 & 1.1 \\
\hline \multicolumn{8}{|c|}{ For glycopyrrolate peak } \\
\hline Condition & As such & + Flow & -Flow & + Temp & -Тemp & $+\mathrm{Org}$ & $-\mathrm{Org}$ \\
\hline Area & 37,414 & 34,132 & 41,648 & 36,992 & 37,785 & 37,192 & 37,294 \\
\hline Retention time & 10.62 & 9.66 & 11.75 & 10.14 & 11.07 & 8.2 & 13.93 \\
\hline Theoretical plates & 6,208 & 5,683 & 6,090 & 5,911 & 5,491 & 5,426 & 5,555 \\
\hline Tailing factor & 1 & 1 & 1 & 1 & 1.1 & 1.1 & 1.1 \\
\hline \multicolumn{8}{|c|}{ Table 11: Forced degradation data } \\
\hline \multicolumn{8}{|c|}{ For formoterol fumarate } \\
\hline Condition & As such & Acid deg. & Alkali deg. & \multicolumn{2}{|c|}{ Peroxide deg. } & Humidity deg. & UV deg. \\
\hline$\%$ assay & 99.3 & 75.3 & 97 & \multicolumn{2}{|c|}{94.2} & 95.3 & 95 \\
\hline$\%$ degradation & 0 & 24 & 2.3 & \multicolumn{2}{|l|}{5.1} & 4 & 4.3 \\
\hline \multicolumn{8}{|c|}{ For glycopyrrolate } \\
\hline$\%$ assay & 100.3 & 89.1 & 82.5 & 98.2 & & 98.2 & 98 \\
\hline$\%$ degradation & 0 & 11.2 & 17.8 & 2.1 & & 2.1 & 2.3 \\
\hline
\end{tabular}

\section{Specificity}

The developed method's specificity was established by determining active components' peak purity in standard preparation and test preparation, using a photo diode array (PDA) detector. This is done using an assay sample and referred for deposition of emitted dose test.

There is no interference found at the retention time of analyte peaks in blank and placebo preparation. The purity of analyte peaks for all degradation conditions is greater than 990 for all degradation conditions. Data in Table 11 represents that formoterol is degraded in acid hydrolysis conditions. Glycopyrrolate degrades in alkali hydrolysis condition. The above observations indicate that the method is specific for its intended purpose.

\section{DISCUSSION}

During the literature review of different methods of aerosol dosage forms, previously reported work was found with gradient elution method having long runtime, higher solvent usage, and dual-wavelength for elution of these drugs.
In the present study, the isocratic reversed-phase HPLC method was developed and validated as per present ICH guidelines for the quantitative determination of in vitro deposition of emitted dose for formoterol fumarate and glycopyrrolate dry powder inhaler aerosol pharmaceutical dosage form. We used sodium sulfate combined with ion exchanger salt 1-hexane sulfonic acid sodium and sulfuric acid for this study. By optimizing the solvent ratio with these reagents, we achieved retention of formoterol peak at about 4 minutes and glycopyrrolate peak at about 11 minutes with theoretical plates more than 4,000 and tailing factor about one, for both analyte peaks. Hence, we could complete the method in 20 minutes runtime with isocratic elution.

There was a challenge of getting an optimum response. The label claim of this dry powder inhalation dosage form used for this study is very low (25 micrograms for glycopyrrolate and 6 micrograms for formoterol fumarate per respicap). We achieved an optimum area response by optimizing a single wavelength of $215 \mathrm{~nm}$. Linearity and accuracy study also performed for very 
vast concentration range, 10 to $150 \%$ of $0.6 \mu \mathrm{g} / \mathrm{mL}$ for formoterol fumarate, and $2.5 \mu \mathrm{g} / \mathrm{mL}$ for glycopyrrolate and achieved sound results, which makes the method more attractive, cost-effective, and can be utilized for different concentrations.

\section{CONCLUSION}

Based on all the above validation data obtained, it can be concluded that the developed method is simple, robust, specific, precise, rugged, accurate, and linear within the performed range and is very much suitable for its intended purpose. This validated method can be useful for combined estimation of formoterol fumarate and glycopyrrolate analytes in multiple industrial, as well as, academic applications. The detailed illustration of all present study parameters will also be useful to research scholars for easy understanding of validation practices.

\section{ACKNOWLEDGMENTS}

The authors of the current work wish to acknowledge the management of Zydus Cadila Healthcare Limited for supporting this work and are grateful to their colleagues from the Analytical Research and Development Laboratory.

\section{REFERENCES}

1. Ghany MF, Hussein LA, Magdy N, Yamani HZ. Simultaneous spectrophotometric determination of indacaterol and glycopyrronium in a newly approved pharmaceutical formulation using different signal processing techniques of ratio spectra. Spectrochimica Acta Part A: molecular and Biomolecular Spectroscopy. 2016 Mar 15;157:251-257.

2. Tamási L, Szilasi M, Gálffy G. Clinical effectiveness of budesonide/ formoterol fumarate Easyhaler ${ }^{\circledR}$ for patients with poorly controlled obstructive airway disease: a real-world study of patient-reported outcomes. Advances in therapy. 2018 Aug 1;35(8): $1140-1152$

3. Lu Y, Sun Z, Zhang Y, Chen X, Zhong D. Simultaneous quantification of 22R and 22S epimers of budesonide in human plasma by ultra-highperformance liquid chromatography-tandem mass spectrometry: application in a stereoselective pharmacokinetic study. Journal of Chromatography B. 2013 Mar 15;921:27-34.
4. Salem YA, Hammouda ME, El-Enin MA, El-Ashry SM. Multiple analytical methods for determination of formoterol and glycopyrronium simultaneously in their novel combined metered dose inhaler. BMC chemistry. 2019 Dec;13(1):75.

5. Snyder LR, Kirkland JJ, Dolan JW. Introduction to modern liquid chromatography. John Wiley and Sons; 2011 Sep 20.

6. Ravi Sankar S. Text book of pharmaceutical analysis. 4th ed., Rx publication, Tirunelveli, 2005.

7. Sharma BK. Instrumental methods of chemical analysis. 23rd ed., Goel publishinghouse, meerut, 2004.

8. Guideline IH. Validation of analytical procedures: text and methodology. Q2 (R1). 2005 Nov;1:1-5.

9. Elder D.ICH Q6A Specifications: test procedures and acceptance criteria for new drug substances and new drug products: chemical substances. ICH Quality Guidelines: An Implementation Guide. 2017 Sep 27:433-466.

10. United States Pharmacopoeia 30 and National formulary 25. Rockville (MD): United State Pharmacopoeia Convention, 2007.

11. Pharmacopiea I. Government of India, ministery of Health and Family welfare, New Delhi. The controller of publication. 1996

12. Kotak RK, Pandya CV, Pandya AC, Thakur B, Laddha R. Solubility study Of Formoterol Fumarate Dihydrate, Glycopyrrolate And Budesonide Drugs As A practical Tool For Analytical Method Development. International Journal of Technical Innovation in Modern Engineering and Science. 2019; 5-5:386-388

13. Salem YA, Shaldam MA, El-Sherbiny DT, El-Wasseef DR, El-Ashry SM. Simultaneous Determination of Formoterol Fumarate and Budesonide Epimers in Metered Dose Inhaler Using Ion-Pair Chromatography. Journal of chromatographic science. 2017 Nov 1;55(10):1013-1020.

14. Pai N, Patil SS. Development and validation of RP-HPLC method for estimation of formoterol fumarate and budesonide in pressurised meter dose inhaler form. Der Pharmacia Sinica. 2013;4:15-26.

15. Farid NF, Abdelwahab NS. Development and Validation of Different Chromatographic Methods for Analysis of Cabergoline in the Presence of Its Degradation Products: Studying Degradation Profile. Chromatographia. 2019 Oct 1;82(10):1555-1569.

16. Chatrabhuji P, Pandya C, Patel M. HPLC Method for Determination of APIs in pharmaceutical formulation. Lulu. com; 2015 Apr 17.

17. Patel VA, Pandya CV, Pandya AC, patel D, Patel Z. Concurrent determination of Tenligliptin Hydrobromide Hydrate and Metformin Hydrochloride Development and Validation by UV-VIS Spectrophotometry in Bulk and Pharmaceutical Dosage form. International Journal of Technical Innovation in Modern Engineering and Science. 2019;5-3:296-303.

18. Kale NR, Pingle AP, Mirza JA, Dhongade GN. Development and validation of stability-indicating RP-HPLC method for simultaneous estimation of formoterol fumarate and budesonide in metered dose inhaler formulation. World Journal of Pharmaceutical Research. 2014 Jun 20;3(6):1386-1399.

HOW TO CITE THIS ARTICLE: Kotak RK, Pandya CV, Pandya AC. Validation of in vitro deposition of emitted dose method for simultaneous estimation of formoterol fumarate and glycopyrrolate in combined dry powder inhaler aerosol pharmaceutical dosage form. Int. J. Pharm. Sci. Drug Res. 2020;12(5):501-508. DOI: 10.25004/IJPSDR.2020.120511 